\title{
Nanoimprinting reflow modified moth-eye structures in chalcogenide glass for enhanced broadband antireflection in the mid-infrared
}

\author{
Lotz, Mikkel ; Needham, Julius; Jakobsen, Mogens H.; Taboryski, Rafael
}

Published in:

Optics Letters

Link to article, DOI:

10.1364/OL.44.004383

Publication date:

2019

Document Version

Publisher's PDF, also known as Version of record

Link back to DTU Orbit

Citation (APA):

Lotz, M., Needham, J., Jakobsen, M. H., \& Taboryski, R. (2019). Nanoimprinting reflow modified moth-eye structures in chalcogenide glass for enhanced broadband antireflection in the mid-infrared. Optics Letters, 44(17), 4383-4386. https://doi.org/10.1364/OL.44.004383

\section{General rights}

Copyright and moral rights for the publications made accessible in the public portal are retained by the authors and/or other copyright owners and it is a condition of accessing publications that users recognise and abide by the legal requirements associated with these rights.

- Users may download and print one copy of any publication from the public portal for the purpose of private study or research.

- You may not further distribute the material or use it for any profit-making activity or commercial gain

- You may freely distribute the URL identifying the publication in the public portal 


\title{
Nanoimprinting reflow modified moth-eye structures in chalcogenide glass for enhanced broadband antireflection in the mid-infrared
}

\author{
Mikkel Lotz, ${ }^{1}$ (i) Julius Needham, ${ }^{1}$ Mogens H. Jakobsen, ${ }^{2}$ and Rafael Taboryski ${ }^{1, *}$ (i) \\ ${ }^{1}$ DTU Nanolab, Technical University of Denmark, Kongens Lyngby, DK-2800, Denmark \\ ${ }^{2}$ DTU Department of Chemistry, Technical University of Denmark, Kongens Lyngby, DK-2800, Denmark \\ *Corresponding author: rata@dtu.dk
}

Received 11 July 2019; accepted 1 August 2019; posted 9 August 2019 (Doc. ID 371296); published 29 August 2019

We report on the progress towards developing a new method for fabricating more efficient, broadband antireflective (AR) moth-eye structures in $\mathrm{As}_{2} \mathrm{Se}_{3}$ via a direct nanoimprinting technique. Thermal reflow is used during mold fabrication to reshape a conventional deep-ultraviolet lithography in order to promote a pattern transfer of "secant ogive"-like moth-eye structures. Once replicated, structures modified by reflow displayed greater AR efficiency compared to structures replicated by a conventional mold, achieving the highest spectrum-averaged transmittance improvement of 12.36\% from 3.3 to $12 \mu \mathrm{m}$. @ 2019 Optical Society of America

https://doi.org/10.1364/OL.44.004383

Provided under the terms of the OSA Open Access Publishing Agreement

When a beam of light strikes the surface of an optical medium such as a lens, a fraction of the light is reflected due to Fresnel reflection. In the mid-infrared (mid-IR) region, this reflection can make up a sizeable portion of the combined losses due to the extensive dependency on high-index materials such as chalcogenide glasses (ChGs). ChG is a unique group of IR transparent materials that generally boasts low optical losses combined with a wide transparency window that, depending on the composition, extends from the short-wavelength IR into the mid- to long-wavelength IR [1]. However, it is the thermomechanical properties of ChGs, which set them apart from other IR optical materials such as germanium, zinc sulfide, and zinc selenide. As a glass type material, $\mathrm{ChG}$ becomes malleable when heated above its glass transition temperature; hence, its compatibility with low-cost replicative techniques such as nanoimprinting [2-6] and precision glass molding [7-9], as well as fiber drawing used to manufacture mid-IR optical fibers $[8,10]$.

While $\mathrm{Ge}_{28} \mathrm{Sb}_{12} \mathrm{Se}_{60}$ (BD2) is the current go-to choice when it comes to manufacturing molded $\mathrm{ChG}$ lenses, the rising cost of germanium has enabled arsenic-triselenide $\left(\mathrm{As}_{2} \mathrm{Se}_{3}\right)$ to become a low-cost alternative, as it contains no germanium and has a lower glass transition temperature, reducing manufacturing costs [11]. $\mathrm{As}_{2} \mathrm{Se}_{3}$ is a well-established $\mathrm{ChG}$ composition with a refractive index $n \sim 2.78$ (at $6 \mu \mathrm{m}$ ) and a low-loss window extending from $\sim 1-12 \mu \mathrm{m}$ [12] but, because of its relatively high refractive index, it suffers a $22 \%$ reduction in transmission per air-glass interface due to Fresnel reflection. While commercial thin-film coatings have been developed to suppress reflection in the visible and near-IR, few solutions currently exist for $\mathrm{ChG}$ applications operating in the mid-IR, since these coating materials and processes are either chemically or thermomechanically incompatible [13-16]. Nevertheless, impressive results have been demonstrated on InP substrates using a rather complicated thinfilm coating scheme [17].

When an optical element is textured with random or periodic sub-wavelength structures, it forms a graded index matching layer between the air and substrate. The resulting effect is a reduction in the amount of light reflected, a so-called antireflective (AR) effect. The phenomenon is known as the "moth-eye effect," named after the discovery of such structures on the eyes of nocturnal moths, where it is believed to be used as camouflage against predators and to improve night vision $[18,19]$. Studies have proposed, via simulations and experiments that, of the three primitive shapes, conical, parabolic and Gaussian-bell like profiles, a parabolic-shaped moth-eye profile arranged in a close-packed hexagonal array, yields the most effective broadband antireflection [19-21].

In a recent study, we demonstrated a simple method for structuring the surface of bulk ChG windows with an AR surface texture [5]. While broadband antireflection was ultimately achieved, the study also revealed shortcomings, which left taller moth-eye structures partially replicated, resulting in lower performances. Thus, the full capability of this technique was not fully demonstrated. We now report on the progress towards developing superior AR surface textures, which display greater efficiency over a significantly broader spectrum. This is accomplished by introducing several changes to the microstructure design and methodology.

First, a new photolithography post-processing step, thermal reflow [22], is added to the mold fabrication process, promoting the transfer of a "secant ogive"-like microstructure profile. Secondly, a higher temperature and pressure, as well as a cooldown step, are employed in the nanoimprint process, facilitating replication of higher aspect ratio structures while simultaneously reducing the extent of fracture defects in the textured surface. 


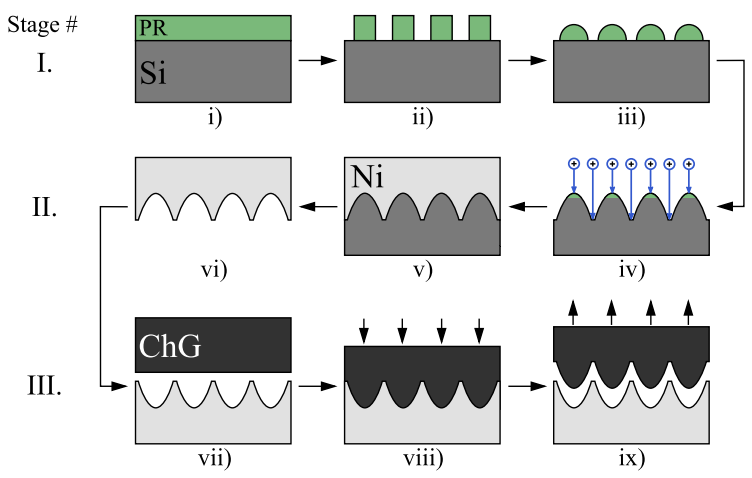

Fig. 1. Process flow diagram of the mold fabrication method and subsequent $\mathrm{ChG}$ sample structuring.

The fabrication process used to make the molding tool, apart from the addition of a thermal reflow step, has previously been described in detail in Ref. [5]. However, in short, the process flow shown in Fig. 1, is divided into three stages. First stage is lithography, where an etch mask is defined and then modified by thermal reflow. The second stage is pattern transfer and electroforming, where the developed resist is transferred to a silicon ( $\mathrm{Si}$ ) substrate by dry etching, forming a stamp, which is subsequently electroformed and dissolved in a potassium hydroxide solution to produce a nickel (Ni)-based mold. The last stage is nanoimprinting, where the fabricated mold is used to replicate a mirror image texture on the ChG surface.

Polished and uncoated stoichiometric $\mathrm{As}_{2} \mathrm{Se}_{3}$ windows (AMTIR-2, Ø25.4 mm, 2 mm thick) supplied by Amorphous Materials Inc., U.S., were used to test the replication of AR surface textures. The setup, shown in Fig. 2(a), was employed to carry out the nanoimprint process, which uses a hotplate to heat the sample and mold, while a piston, mounted on a linear actuator and driven by a DC motor, was used to apply pressure. An acrylic dome was used to nanoimprint in an inert $\left(N_{2}\right)$ atmosphere. A cross-sectional sketch of the sample assembly is shown in Fig. 2(b). This assembly consists primarily of aluminum parts that have thermal expansion coefficients close to

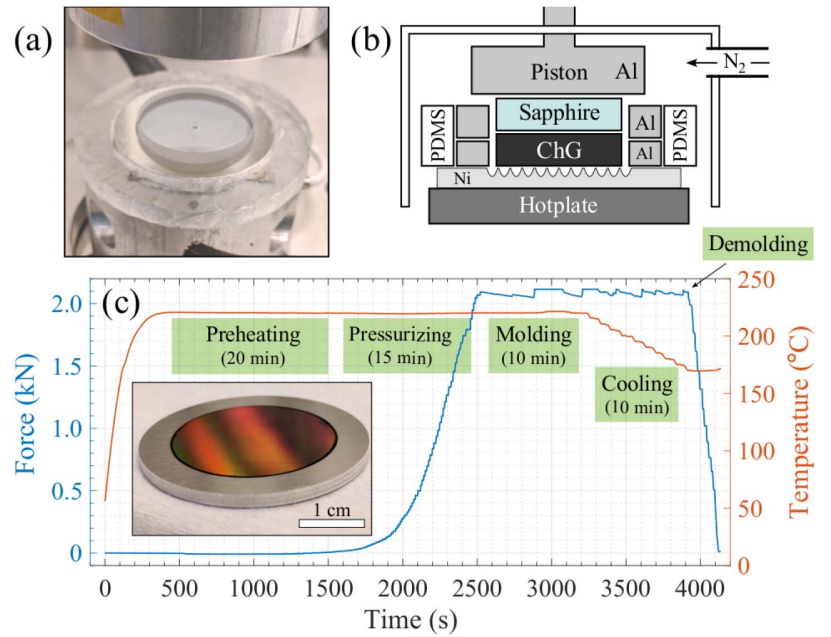

Fig. 2. (a) Nanoimprint setup. (b) Cross-sectional sketch of the assembly. (c) Plot of the piston force and hotplate temperature applied during the five phases of nanoimprinting. The insert shows a photograph of a textured ChG sample with the aluminum ring surrounding it. that of ChG. A sapphire window (WG31050, Thorlabs Inc., U.S.) was placed on the opposite side to ensure that this remained as pristine as possible.

The nanoimprinting procedure has five phases, which are highlighted in Fig. 2(c): preheating, pressurizing, molding, cooling, and demolding. Preheating the assembly to the intended molding temperature of $220^{\circ} \mathrm{C}$ for $20 \mathrm{~min}$ before applying pressure ensured that the system reached a stable and uniform temperature, giving the sample and aluminum parts ample time to thermally expand before initiating. The piston was then engaged in small increments to produce a slowly increasing pressure on the ChG sample. After roughly $15 \mathrm{~min}$, the applied force reached $\sim 2.1 \mathrm{kN}$, corresponding to $416 \mathrm{~N} / \mathrm{cm}^{2}$. This was maintained for $10 \mathrm{~min}$, during which a slow decrease in pressure is observed, as the sample deforms. Therefore, the position of the piston is continually adjusted to maintain the pressure. In the cooling phase, the temperature was slowly ramped down to $165^{\circ} \mathrm{C}$, at which point the piston was disengaged, removing pressure on the sample entirely. Demolding so close to the glass transition temperature of $\mathrm{As}_{2} \mathrm{Se}_{3}\left(T_{g}=167^{\circ} \mathrm{C}\right)$ minimizes the buildup of stress between the glass and mold, caused by a difference in thermal expansion between the two. This makes demolding easier and reduces the risk of introducing fracture defects in the newly replicated surface $[23,24]$.

Thermal reflow is a gradual effect that reshapes the developed resist into a new and rounded profile. By adjusting the temperature and duration of the process, the resulting profile can be tailor-made to a given specification. Therefore, we begin by examining the different resist shapes which can be achieved by adjusting the reflow temperature, while keeping the duration constant at $90 \mathrm{~s}$. For this test, we used the conventional deep-ultraviolet photoresist shown in Fig. 3(a), which consists of a hexagonally arranged resist pattern with a feature pitch $p=1300 \mathrm{~nm}$ and an initial resist thickness $t=1000 \mathrm{~nm}$. Three wafers containing the developed photoresist were placed on a hotplate and subsequently exposed to three different reflow temperatures, $T_{r}=160^{\circ} \mathrm{C}, 165^{\circ} \mathrm{C}$, and $170^{\circ} \mathrm{C}$, as shown in Figs. 3(b)-3(d). At $T_{r}=160^{\circ} \mathrm{C}$, we saw only subtle changes to the resist, as the resist pillar appeared slightly rounded near the top edge. At $T_{r}=165^{\circ} \mathrm{C}$, the resist showed moderate signs of thermal reflow, as the pillar appeared both shorter and rounder, as well as exhibiting a slightly larger feature footprint. Finally, at $T_{r}=170^{\circ} \mathrm{C}$, a substantial amount of reflow was observed, with the resist pillar now shaped as a spherical cap and a footprint which appears considerably larger than its non-reflow counterpart.

The pronounced smoothing effect, seen as the resist is melted, is useful for the fabrication of the mold, since a smooth resist translates into a smoother mold surface, thus reducing the surface-to-volume ratio between the mold and the sample. Likewise, the observed broadening of the resist is also beneficial (a)

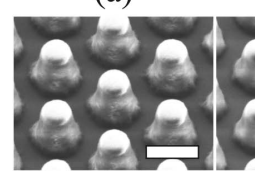

(b)

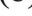

(c) (d)
Fig. 3. SEM images of the deep-ultraviolet lithography with $t=1000 \mathrm{~nm}$ and $p=1300 \mathrm{~nm}$, viewed at $30^{\circ}$ tilt. (a) Reference lithography without reflow. (b)-(d) SEM images of the lithography after subjecting it to reflow temperatures of $160^{\circ} \mathrm{C}, 165^{\circ} \mathrm{C}$, and $170^{\circ} \mathrm{C}$ for $90 \mathrm{~s}$, respectively. The length of all scalebars is $1 \mu \mathrm{m}$. 
for AR surface textures, as wider structures with higher packing densities have been demonstrated to increase the overall efficiency of the AR texture [19]. The only clear disadvantage of using reflow is the considerable reduction in resist thickness which inevitably also occurs. This is especially problematic when used in broadband AR applications, as it will translate to smaller structures being transferred to the $\mathrm{Si}$ substrate and, thus, a substantial reduction in the AR bandwidth once replicated. However, simply applying a thicker layer of photoresist at the initial stage of fabrication to compensate for the height reduction helps solve this problem, as we shall demonstrate in the next section.

The reference resist pattern and the resist pattern with extensive resist reflow $\left(T_{r}=170^{\circ} \mathrm{C}\right)$, were then used as etch masks in a dry-etch process to fabricate an array of tightly packed microstructures on the surface of the Si substrate. These transferred Si moth-eye structures are shown in Fig. 4. As predicted, the reference resist pattern, with its greater thickness, produced a tall, segmented taper, whereas the reflow modified resist yielded a short, continuous taper, best described by a secant ogive function with a sharpness of 1.57. An examination of the two reliefs from the top also revealed a slight difference in their respective packing densities, as indicated in Figs. 4(b) and 4(d). With a gap size of $(85 \pm 5)$ and $(50 \pm 5) \mathrm{nm}$ for the reference and reflow modified microstructures, respectively, the corresponding increase in density is $\sim 5 \%$ from 0.87 to 0.92 . These geometrical differences are also captured by the cross-sectional line-scans on the subsequent Ni-mold surfaces shown in Fig. 5(a). These profiles were extracted from topographic images obtained by atomic force microscopy (AFM, NX20, Park Systems, Korea) fitted with a tilt compensated high aspect ratio scanning probe (AR5TNCHR, Nanosensors, Switzerland).

To address the reduction in structural height, the reflow experiment was repeated, but this time a compromise was struck between reshaping the resist and maintaining a reasonable resist pillar height. Reducing the reflow temperature

(a)

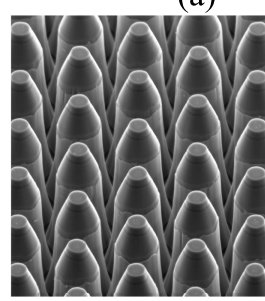

(c)

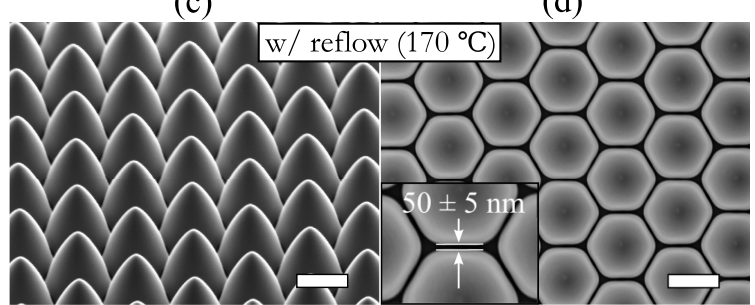

Fig. 4. SEM images of the Si microstructures transferred from an etch mask with $t=1000 \mathrm{~nm}$ and $p=1300 \mathrm{~nm}$. Structures transferred by the reference pattern, viewed at (a) $45^{\circ}$ tilt and (b) $0^{\circ}$ tilt. Structures transferred by the reflow modified etch mask with $T_{r}=170^{\circ} \mathrm{C}$, viewed at (c) $45^{\circ}$ tilt and (d) $0^{\circ}$ tilt. The inserts show the measured gap between structures. The length of all scalebars is $1 \mu \mathrm{m}$. to $T_{r}=165^{\circ} \mathrm{C}$, combined with an increase in the initial resist thickness to $1400 \mathrm{~nm}$, yielded a pattern transfer in Si resembling that of the previous reflow modified microstructure (\#1), but with an ogive sharpness of $\sim 2.7$. The structure height is also much closer to that of the reference structure (\#3), as shown by the measured AFM profile given in Fig. 5(a). SEM images of this "height compensated" Si microstructure array and the subsequent inverted $\mathrm{Ni}$-mold surface are shown in Fig. 5(b) and Fig. 5(c), respectively.

Finally, in order to determine how the addition of the thermal reflow step affects the optical properties, each of the three fabricated molds was used to texture a single surface of an $\mathrm{As}_{2} \mathrm{Se}_{3}$ window. By measuring the 0th-order transmittance, $T$, before and after applying a surface texture, its AR properties can be studied in a side-by-side comparison with the two other mold designs. The transmittance measurements were obtained using a Fourier-transform infrared spectrometer (Spectrum 100 FT-IR, PerkinElmer, U.S.) fitted with a sample holder attached to a rotating base plate. Furthermore, the normal incidence measurement was conducted at an incident angle of $\theta=6^{\circ}$ to avoid introducing a systematic error due to interreflection.

The optical results collected from the experiments are given in Figs. 6(a)-6(c), while SEM images of the three replicated surface textures are shown in Figs. 6(d)-6(f). The theoretical blank window transmittance is also plotted for reference, given by $T_{\text {blank }}=\frac{(1-R(n))^{2}}{1-R(n)^{2}}$, where $R(n)$ is the reflectance at the air- $\mathrm{As}_{2} \mathrm{Se}_{3}$ interface. The maximum transmittance attainable is defined as $T_{\max }=1-R(n)$, while the transmittance improvement is defined as $\Delta T=T_{\text {imp }}-T_{\text {ref }}$, where $T_{\text {ref }}$ and $T_{\text {imp }}$ are the measured transmittance before and after texturing.

With identical design periods, the measured transmittance spectra of the three textured samples exhibit diffraction at incident wavelengths $\lambda<3.3 \mu \mathrm{m}$, shown as the sudden drop in the 0th-order transmittance. However, at $\lambda \geq 3.3 \mu \mathrm{m}$, each texture displays its own characteristic AR properties.

Using the profile line-scans of the mold structures given in Fig. 5(a) as the basis for a rigorous coupled-wave analysis (RCWA) model, we were able to approximately reproduce
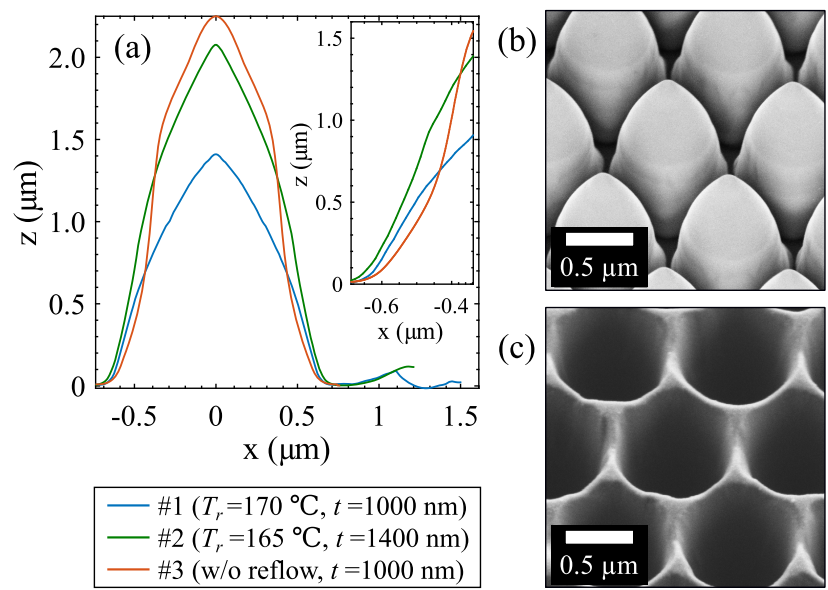

(c)

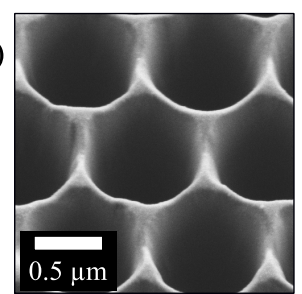

Fig. 5. (a) Plot of the inverted AFM profile line-scans for the three fabricated Ni-mold structures (plotted in 1:1 aspect ratio). The inset shows an enlarged view of the sidewall. (b) SEM image of the transferred $\mathrm{Si}$ microstructures using a resist pattern with $t=1400 \mathrm{~nm}$, $p=1300 \mathrm{~nm}$, and $T_{r}=165^{\circ} \mathrm{C}$, viewed at $30^{\circ}$ tilt. (c) SEM image of the final Ni-mold surface using (b) as a preform, viewed at $30^{\circ}$ tilt. 

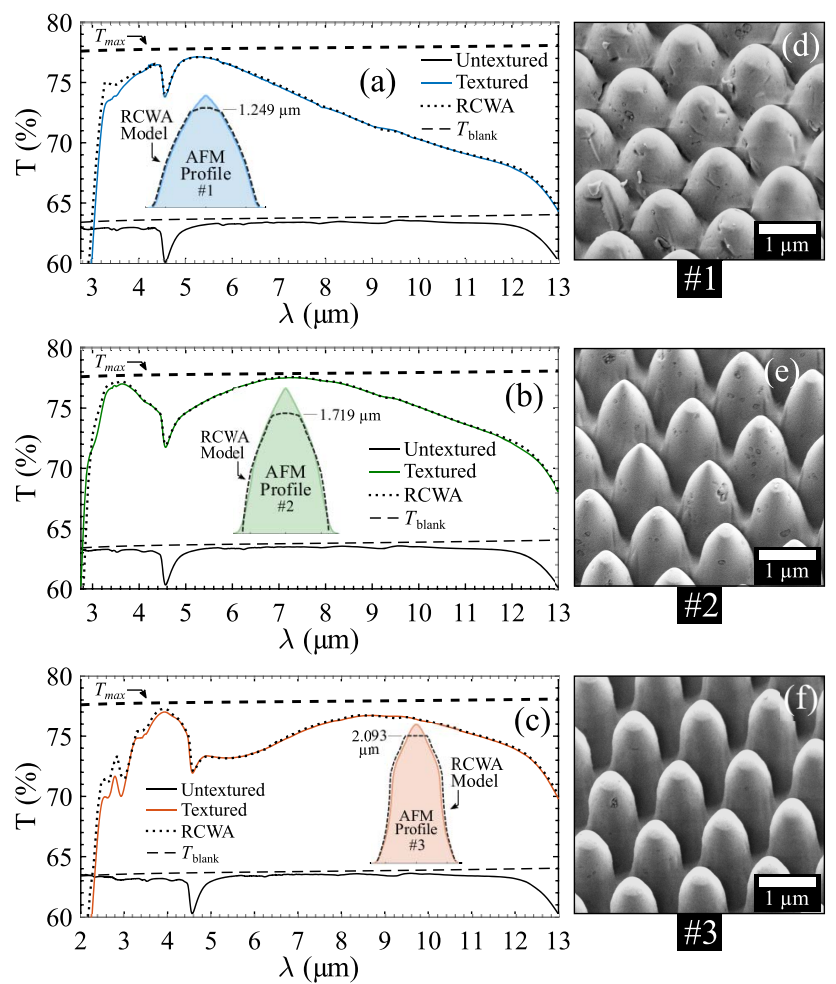

Fig. 6. Plots of the measured 0 th-order transmittance, $T$, as a function of the incident wavelength before and after texturing the ChG samples using mold (a) \#1, (b) \#2, and (c) \#3. The inserts show the RCWA model profile used to reproduce the measured T. (d)-(f) SEM images of the three replicated surface textures from molds $\# 1$, \#2, and $\# 3$, respectively, viewed at $30^{\circ}$ tilt.

the three measured results. The RCWA models, shown as inserts in Figs. 6(a)-6(c), suggest a replication height of $1249 \mathrm{~nm}$, 1719 and $2093 \mathrm{~nm}$ for $\# 1, \# 2$ and $\# 3$, respectively, which is roughly equivalent to the average measured structure heights of $1324 \pm 58,1751 \pm 87$, and $2127 \pm 56 \mathrm{~nm}$, obtained by SEM imaging. Superimposing each model over its corresponding mold profile furthermore suggests that most of the mold cavity was successfully filled and replicated on the glass surface. Note that the spectra, both before and after imprinting, exhibit absorption at $4.6 \mu \mathrm{m}$, which correspond to Se-H impurities from when the glass was originally synthesized and, therefore, is not a product of the nanoimprinting process.

Calculating the spectrum-averaged transmittance improvement, $\langle\Delta T\rangle$, from 3.3 to $12 \mu \mathrm{m}$, we find that texture \#2 and \#3 perform almost identically, despite the height profile of texture \#2 being $\sim 18 \%$ shorter. For texture \#2, the average performance across different samples was $\langle\Delta T\rangle=$ $(12.16 \pm 0.17) \%$, whereof the best of the tested samples exhibited a $\langle\Delta T\rangle$ of $12.36 \%$ [shown in Fig. 6(b)]. For texture $\# 3$, the average performance across samples was $\langle\Delta T\rangle=$ $(11.93 \pm 0.06) \%$, with the best sample exhibiting a $\langle\Delta T\rangle$ of $11.95 \%$ [shown in Fig. 6(c)]. Therefore, it is evident that although texture \#3 has a slightly wider spectrum better suited for transmission from 3.3 to $12 \mu \mathrm{m}$, the enhanced AR properties produced by the reflow modified structures enables texture \#2 to match the average AR performance of texture \#3, and even surpass it. Moreover, since texture $\# 2$ has a lower profile, it is also less taxing to replicate via nanoimprinting.
Nevertheless, both results constitute a significant improvement over the previous best result for the same spectral range of $10.14 \%$ (extracted from data published in Ref. [5]).

In conclusion, we have demonstrated that by using thermal reflow to reshape an etch mask, we can tailor it to promote etched secant ogive-shaped moth-eye structures in $\mathrm{Si}$. Once inverted onto a Ni-mold and replicated on a ChG surface using a specialized nanoimprint process, these reflow modified structures display enhanced AR properties compared to textures replicated by a mold made using a conventional mold fabrication process.

Funding. Innovationsfonden (4107-00011A).

\section{REFERENCES}

1. J. S. Sanghera, L. B. Shaw, L. E. Busse, V. Q. Nguyen, P. C. Pureza, B. C. Cole, B. B. Harrison, I. D. Aggarwal, R. Mossadegh, F. Kung, D. Talley, D. Roselle, and R. Miklos, Fiber Integrated Opt. 19, 251 (2000).

2. T. Kohoutek, J. Orava, A. Greer, and H. Fudouzi, Opt. Express 21, 9584 (2013).

3. S. Danto, E. Koontz, Y. Zou, T. O. Ogbuu, B. Gleason, P. Wachtel, J. D. Musgraves, J. Hu, and K. Richardson, Proc. SPIE 8884, $88841 \mathrm{~T}$ (2013).

4. B. D. MacLeod, D. S. Hobbs, and E. Sabatino, Proc. SPIE 8016 , 80160Q (2011).

5. M. R. Lotz, C. R. Petersen, C. Markos, O. Bang, M. H. Jakobsen, and R. Taboryski, Optica 5, 557 (2018).

6. A. B. Seddon, N. S. Abdel-Moneim, L. Zhang, W. J. Pan, D. Furniss, C. J. Mellor, T. Kohoutek, J. Orava, T. Wagner, and T. M. Benson, Opt. Eng. 53, 071824 (2014).

7. D. H. Cha, H. J. Kim, Y. Hwang, J. C. Jeong, and J. H. Kim, Appl. Opt. 51, 5649 (2012).

8. D. W. Hewak, D. Brady, R. J. Curry, G. Elliott, C. C. Huang, M. Hughes, K. Knight, A. Mairaj, M. N. Petrovich, R. E. Simpson, and C. Sproat, Photonic Glasses and Glass-Ceramics (Research Signpost, 2010), p. 29.

9. X. H. Zhang, Y. Guimond, and Y. Bellec, J. Non-Cryst. Solids 326, 519 (2003).

10. W. H. Kim, V. Q. Nguyen, L. B. Shaw, L. E. Busse, C. Florea, D. J. Gibson, R. R. Gattass, S. S. Bayya, F. H. Kung, G. D. Chin, R. E. Miklos, I. D. Aggarwal, and J. S. Sanghera, J. Non-Cryst. Solids 431, 8 (2016).

11. J. Huddleston, J. Novak, W. V. Moreshead, A. Symmons, and E. Foote, Proc. SPIE 9451, 945110 (2015).

12. Amorphous Materials Inc., "AMTIR-2 data sheet."

13. E. Brinley, S. Seal, R. Folks, E. Braunstein, and L. Kramer, J. Vac. Sci. Technol. A 24, 1141 (2006).

14. S. Shabahang, F. A. Tan, J. D. Perlstein, G. Tao, O. Alvarez, F. Chenard, A. Sincore, L. Shah, M. C. Richardson, K. L. Schepler, and A. F. Abouraddy, Opt. Mater. Express 7, 2336 (2017).

15. D. S. Hobbs and B. D. MacLeod, Proc. SPIE 5786, 349 (2005).

16. P. Lalanne and G. M. Morris, Proc. SPIE 2776, 300 (1996).

17. Y. Matsuoka, S. Mathonneire, S. Peters, and W. T. Masselink, Appl. Opt. 57, 1645 (2018).

18. C. G. Bernhard, J. Boëthius, G. Gemne, and G. Struwe, Nature 226, 865 (1970).

19. D. G. Stavenga, S. Foletti, G. Palasantzas, and K. Arikawa, Proc. R. Soc. London 273, 661 (2006).

20. Y. J. Yoo, K. S. Chang, S. W. Hong, and Y. M. Song, Opt. Quantum Electron. 47, 1503 (2015).

21. Y. M. Song, S. J. Jang, J. S. Yu, and Y. T. Lee, Small 6, 984 (2010).

22. H. Schift, C. Spreu, A. Schleunitz, and J. Lee, Microelectron. Eng. 88, 87 (2011).

23. Y. Hirai, S. Yoshida, and N. Takagi, J. Vac. Sci. Technol. B 21, 2765 (2003).

24. A. Kolew, M. Heilig, M. Schneider, D. Münch, R. Ezzat, N. Schneider, and M. Worgull, Microsyst. Technol. 20, 1967 (2014). 